\title{
A Study on the Application of "Flipping Class" in Teaching Chinese as a Foreign Language
}

\author{
Kunhu Wu \\ College of Humanities, Sichuan Agricultural Uniersity, Ya’an City, Sichuan Province, 625014, China
}

Keywords: Flipping class; Chinese as a foreign language; Teaching; Application

\begin{abstract}
With the development of educational informatization, the teaching method of flipped classroom is gradually applied to teaching activities, which also provides a new teaching mode for teaching Chinese as a foreign language. The flipping class is a kind of teaching exploration that reverses the course and the extracurricular learning activities, and the essence of it is to turn the traditional teaching focus from the transfer of knowledge to the absorption of knowledge, so as to realize the teaching idea of "student centered". Based on the author's learning and practical experience, this paper first analyzed the feasibility of the application of the "flipped class" teaching mode in teaching Chinese as a foreign language, and then put forward the feasible application strategies, and finally summarized the typical problems in flipping classroom teaching mode.
\end{abstract}

\section{The Feasibility of the Application of the "Flipped Class" Teaching Mode in Teaching Chinese as a Foreign Language}

\subsection{The teaching of Chinese as a foreign language has the hardware conditions for the implementation of the "flipped class"}

"Flipping class" is the product of the multimedia age, which uses modern technology such as network to help teaching, therefore, a relatively complete multimedia technology platform is the prerequisite for the implementation of the "overturned classroom". At present, in the practice of teaching Chinese as a foreign language, students are generally adults, and most of them have personal computers, which lays a material foundation for the implementation of "flip classroom".

\subsection{The basic rules of teaching Chinese as a foreign language and the "flipped class" are essentially adapted to each other}

First of all, the "flipping class" can fully implement the principle of "speaking more carefully" and improve the efficiency of students' learning. Due to the full and efficient pre class preview in the "flipped class", teachers do not need to worry too much in class, and they just need little inspiration with little guidance, so a lot of time will be released for students to practice and practice. Jonathan Bergmann and Aaron Sams, representatives in the "flipping" class, once said: "Flipped classroom has changed our teaching practice. We will never give them a lesson for 30-60 minutes in front of students. We may never return to the traditional way of teaching". On the other hand, flipped classroom teaching is a teaching mode based on cooperative learning mode and task-based teaching method, which absorbs many advantages. Communication between teachers and students is no longer the only mode of communication, and it is not even the most important mode of communication. The classroom became the stage for students to communicate with them. The opportunity for students to participate directly in communication will be greatly increased. Therefore, "flipping classroom" teaching can give students the best opportunity to practice. Secondly, the individualized teaching in the "flipped class" can fully arouse the enthusiasm and initiative of the students. One of the outstanding characteristics of teaching Chinese as a foreign language is that students are different from each other. Under the traditional teaching mode, it is difficult for teachers to take care of the needs of different students. In the "flipping classroom", students can learn self-study under the guidance of teaching video and adjust their learning process and progress according to the actual situation. They can also carry out inquiry learning in their 
classroom according to their own thoughts. Students will truly become the center of teaching activities, and the enthusiasm and initiative of learning will undoubtedly be greatly improved.

\section{The Application Strategies of "Flipping Class" in Teaching Chinese as a Foreign Language}

\subsection{The preparatory stage of pre class teaching}

Teaching video (micro class, MOOCs) is made according to the analysis of teaching objectives, teaching contents and teaching objects. Each video is demonstrated with the teacher explaining the way, and the video length control in about 10 minutes. The video is posted on the WeChat public platform 3 days before class. In advance, we design teaching activities, including the theme tasks, activity guides and grouping mechanisms of each class. Under the guidance of teachers, students participate in online courses, retrieve network resources, and do self test exercises by watching video courseware to initially complete the memory and understanding of the course content. The content of memory mainly includes three types: specific knowledge, including the new words in each lesson, grammar points and texts; Procedural knowledge, the use of words and sentences, the use of grammatical points; Metacognitive knowledge, to determine what kind of memory and understanding to memorize and understand these contents. Understand the content of the course, organize and express the content and knowledge in the language of the student's own words, and explain the information exchanged in the video. In this way, students can learn Chinese by mobile phone anytime and anywhere.

\subsection{Application analysis stage in class}

In class, the teacher guides the students to discuss in the course of their study. Through group discussion, students can grasp the knowledge points of teachers' contents, and students can also get help from peers at any time in learning, and complete the course learning content through teamwork. At the application analysis stage, students apply and analyze the knowledge acquired in the previous stage through homework exercises, group display, reflection summary, group competition and other autonomous learning activities. Application refers to the ability to apply the acquired knowledge to new problem situations, for example the use of the same word in different contexts. Analysis refers to decomposing complex knowledge. Students should not only understand the contents of materials, but also understand their structures, such as completing exercises with new learning new words and grammar, retelling texts and writing short passages. In the application analysis stage, internalization of knowledge is completed.

\subsection{Feedback stage after class evaluation}

Within 3 days after class, students feedback questions through WeChat group, QQ group or WeChat public platform, so as to find the deficiency of teaching preparation stage. At this stage, students communicate and evaluate the learning process and results through a summary of the learning activities in the previous stage. The aim is to make all the elements and components as whole, and to combine the various learning and thinking activities that occur under the class as an integration. For example, we apply the conversation learning in the classroom to the real life, and make the feedback after class by recording the video that is conversed with the Chinese. At the same time in this stage, students are presenting their personal understanding of knowledge, and teachers and other students will evaluate their knowledge based on their understanding of knowledge; moreover, they should encourage students to expand extracurricular learning resources, and gradually improve their internalization of knowledge in continuous communication.

\section{Reflection on the Flipping Class Teaching Mode}

\subsection{The problem of students' autonomous learning}

For international students, their main purpose is to study medicine, and the language of instruction is English, which leads some students to be less active in learning Chinese. It is often 
impossible to complete the pre-class preparation assigned by the teacher. This also leads to the lack of participation in group discussion, answer and other links in the class, so it affects the overall teaching progress and effect. Even some students have the initiative of learning, but they are poor in self-learning and can not keep up with the rhythm of teaching. However, the students' autonomous learning ability is the most important factor in the success of the "flipping class" teaching mode. Because this teaching mode subverts the traditional teaching mode based on "teaching", and it has become the "learning" mode. In this process, the student is the leading role and the teacher is a supporting role. Students must consciously complete the learning tasks assigned by teachers after class, so that to initially form their own understanding of the curriculum content; moreover, they can record their own difficulties and put forward these difficult points to the teachers in the classroom, so that to get the help of the teacher and really master what students have learned. If the students lack the autonomy of learning in a random attitude and can not raise any problems, the teacher's teaching is a failure. Therefore, in the course of teaching, teachers should make some real-time and necessary intervention measures. For example, teacher can adopt some appropriate tests, so that students can develop a sense of achievement in their study and make them confident in learning. Moreover, teachers can publicize the student learning progress and the ranking of activity on the WeChat platform every day, and timely praise studious students, or even give appropriate rewards to the students who study hard and make great progress.

\subsection{The problem of teachers' workload}

It is a challenge for teachers to adopt the "flipping class" teaching mode, and it is mainly because that it aggravates the workload of the teachers. First, teachers need a large number of short and pithy homemade teaching video (micro class, MOOCs), and turn all the knowledge points into three-dimensional or real problem or task. At the same time, teachers need to design a reasonable learning guidance program to guide students to master relevant knowledge and skills through problems or tasks. Second, teachers need to develop corresponding learning resources to provide students with sufficient learning support. Third, in the classroom, teachers should also effectively organize the students to find problems in the discussion, solve the problems and guide them to complete the summary and promotion of knowledge. Fourth, teachers should answer the questions raised by the students in time both on the line and on the line at any time. Therefore, in the process of applying flipping class teaching mode, the role transformation of teachers plays a key role.

\subsection{The problem of choosing teaching resources}

In 2011, Salman Khan founded Khan College to set off a whirlwind of online teaching. Since the opened courseware movement (OCW) of the Massachusetts Institute of Technology (MIT), a number of universities, organizations or individuals have emerged in the world to build open educational resources, and a large number of high-quality teaching resources have emerged, such as the Harvard Open course TED educational video and so on. At present, China's various Chinese education websites have flourished in a new tendency. Chinese national excellent courses, university open classes and the university's own campus web sites have also uploaded a lot of Chinese learning materials. These Chinese learning platforms designed and made by professional information technology talents, have provided great help for university teachers, improved the utilization rate of resources, saved manpower and material resources and enabled students to have extensive access to Chinese teaching resources. However, too much miscellaneous resources will make students feel confused. Because these very rich Chinese resources may not be exactly in line with our current curriculum objectives and the content of the course: they are too simple, too profound, too informal or lacking knowledge and so on. Therefore, the problem about how to select high quality and appropriate teaching resources for students to use in the "flipping classroom" in Chinese learning is also an important problem we face.

\section{References}

[1] Zhenying, Zhang Ying. A Study on the Adaptability of Flipping Class Teaching Mode in 
Teaching Chinese as a Foreign Language[J]. Overseas Chinese Education, 2017, (10): 1421-1426.

[2] Liu Jingjing. The Application of the Flipping Class Teaching Mode in the Teaching Chinese Grammar as Foreign Language[J]. Liaoning Economic Management Cadre College. Journal of Liaoning Vocational College of Economics, 2016, (06): 114-116.

[3] Zhou Dongmei. The Characteristics of the Flipping Class and Its Application in the Teaching Chinese as a Foreign Language[J]. Modern Chinese (Language Research Edition), 2016, (09): 108-110.

[4] Liu Jingjing, Guan Yingming. Feasibility Analysis on the Application of Flipping Class in Teaching Chinese Culture as a Foreign Language[J]. Journal of Liaoning Institute of Education and Administration, 2016,33 (01): 64-66.

[5] Long Li. "Flipping Classroom" Teaching Mode and the Teaching of Oral Chinese as a Foreign Language[J]. Overseas Chinese Education, 2015, (04): 467-475.

[6] Han Bingshuang. The Application of Flipping Class in Teaching Chinese as a Foreign Language[J]. Wisdom, 2015, (25):114.

[7] Ye Lihua. The Application of Flipping Class in Teaching Chinese as a Foreign Language[J]. Journal of Hubei University of Economics (Humanities and Social Sciences Edition: 201-202 205. 